\title{
LA MÁQUiNa de GUERRA NóMADA DEL COVID-19: PAISAJES ESTÉTICOS DEL EPIDEMIOCAPITALISMO
}

\author{
José Manuel Romero Tenorio ${ }^{1}$ \\ William Andres Alvarez ${ }^{2}$
}

Resumen: El coronavirus emergió en un espacio donde tanto el poder que oprime como los oprimidos coinciden en el deseo de vigilar y de ser vigilados, por la acción de las redes sociales, que generan seres superfluos que cambian su intimidad por un like. De ahí que llegamos a un capitalismo donde la epidemiología antecede a la demografía (epidemiocapitalismo): la población se organiza según la lógica ultraindividual de control de la pandemia (pasaportes inmunológicos, supervisión de contagios). Con el concepto de máquina de guerra nómada de Deleuze y Guattari, se analiza el covid-19 como un paisaje estético en el que las territorialidades se definen desde los bordes que contaminan y no desde unas coordenadas que delimitan. Se concluye que este totalitarismo perfecto, al que se denomina net$\mathrm{f}(\mathrm{l}) \operatorname{asci}(\mathrm{x})$ smo, por tener como acicate el ocio, puede transitar hacia formas de disidencias.

Palabras clave: Deleuze. Guattari. Coronavirus. Nomadología. Net-(fl)asc(ix)smo.

\section{A la memoria del profesor Wenceslao Castańares Burcio,}

Quasi nanos gigantium humeris insidentes

\footnotetext{
1 Profesor asociado en la Facultad de Ciencias Humanas, Universidad del Atlántico, Atlántico Colombia. (D) https://orcid.org/0000-0003-0088-6246. E-mail: josemromero@mail.uniatlantico. edu.co.

2 Investigador Posdoctoral, Departamento de Antropología, Universidad Nacional de Colombia, Bogotá - Colômbia. (D) https://orcid.org/0000-0002-3716-4936. E-mail: williamlogia@gmail.com.

https://doi.org/10.1590/0101-3173.2021.v44n4.22.p267
} 


\section{INTRODUCCIÓN}

Que en el corazón financiero mundial se haya instalado un campo abierto de refugiados del coronavirus demuestra que el capitalismo no tiene reparos en organizar de nuevo su topología con recursos simbólicos sorprendentes. En Central Park, a escasas manzanas de la Bolsa de Nueva York, instituciones religiosas, humanitarias y municipales levantaron un pabellón para tratar a enfermos de covid-19, en marzo de 2020. Donald Trump, tras no darle importancia a la pandemia, y en un segundo tiempo atribuirla a un virus enemigo extranjero, reconoció, a principios de abril de 2020, lo irremediable del incremento de muertes, en una nación cuya tarjeta sanitaria coincide con la de crédito. La frialdad de sus palabras encierra una eugenesia que legitima la limpieza social del pobre. Esta presión ideológica condujo, según Slavoj Žižek (2020, p. 22), a "[...] poner en cuarentena a los enemigos que representan una amenaza para la sociedad." La política de Estado frente al coronavirus difiere de país en país. Bolsonaro, en cuyo ascenso al poder tiene mucho que ver el movimiento evangélico (AYRES, 2020), no ha decretado medidas de confinamiento apelando al argumento de que "Dios es brasileño 3 ", mientras que la epidemia se desboca.

El consenso de las autoridades médicas internacionales va en la dirección de decretar, en un primer momento, medidas de confinamiento y el uso masificado de test rápidos para después pautar la salida de la población con una lógica ultraindividual. Se organiza, de este modo, el régimen social y económico según parámetros epidemiológicos: se ritma la geografía social con los actores contagiados, que se suponen inmunizados, llegando a controlar y disponer la proliferación del virus en la sociedad. Se habla de contagios a la carta en perfecta sincronía con el sistema médico para que pueda asimilarlos. Corea del Sur se ha erigido en paradigma del control de la pandemia con precisión de quirurgo. Realizaron, desde el principio, test rápidos que permitieron aislar principalmente a los pacientes asintomáticos, creando, por un lado, aplicaciones móviles con las que se determina el posicionamiento de los contagiados y, por el otro, pasaportes inmunológicos que otorgan el derecho de movimiento a las personas que cuenten con anticuerpos (DE JIMÉNEZ, 2020).

Esta utopía de un Estado epidemiológico ultraindividual que abre la vía al epidemiocapitalismo, la analizo desde el concepto de máquina de guerra

\footnotetext{
3 Fuente: Periódico New York Times, https://www.nytimes.com/es/2020/04/02/espanol/americalatina/bolsonaro-coronavirus-brasil.html.s.
} 
nómada de Gilles Deleuze y Félix Guattari. Según estos autores, el poder recurre a una serie de técnicas de estriaje para ordenar el campo social "[...] que no cesa de ser estriado bajo la coacción de fuerzas que se ejercen en él; pero también desarrolla otras fuerzas y desentrańa nuevos espacios lisos por medio del estriaje." (DELEUZE; GUATTARI, 1980, p. 624). La máquina de guerra sería el modo de alisar lo topográfico. Expuesto de esta manera, se reproducirían unas lógicas dicotómicas poder/contrapoder o centro/periferia. Es el caso de un estudio sobre la cultura RAP de Maheirie, Almir y Bruniere (2017, p. 38-39), quienes la perciben como una máquina de guerra en cuanto “[...] dispositivo a través del cual unos modos de existencias marginalizados generan enunciaciones en lugares que no son los suyos [...] buscando otras formas de ocupar espacios." En la misma línea, Maldonado, Palencia y Silva usan este referente teórico para realizar un análisis literario de la novela Amalia de José Mármol. La lógica es la misma: presuponer que el Estado estría "[...] el espacio sobre el que ejerce su poder contra todo aquello que amenaza desbordarlos (revolución, guerrilla, rebelión) [...] [y finalmente] capturar la máquina de guerra para servirse de sus armas, afectos y enunciados." (MALDONADO; PALENCIA; SILVA, 2016, p. 19-24). Estos autores identifican la máquina de guerra con los gauchescos, incidiendo en la dicotomía poder/contrapoder.

Tras haber recurrido a la fuente original, la obra de Deleuze y Guattari, y cotejándola con las investigaciones filosóficas que versan sobre la misma, postulo, en primera instancia, que la máquina de guerra no constituye una forma de ocupar u ordenar las latitudes desde la marginalidad, sino una praxis política en la cual no hay ni centro ni periferia, tal como apunta Nathan Widder (2018). Este autor hace una crítica a la interpretación de la máquina de guerra a la luz de los postulados de Carl Schmitt, quien la asimila a un instrumento del poder para afianzar el estado de excepción. Paul Patton (2018) insta, en el mismo sentido, a no separar la máquina de guerra de la nomadología. Rechaza la contraposición de un hipotético sedentarismo conservador del Estado con el dinamismo táctico de los grupos de contrapoder. Para Patton, los autores franceses no oponen la nomadología al estriaje permanente del terreno. Todo emplazamiento, añade Patton, articula relaciones de coexistencia de todos los procesos maquínicos (tensiones geodésicas, conjuración-anticipación) que supuran "[...] en la superficie a diferentes grados de intensidad." (PATTON, 2018, p. 217). En la misma línea, para Guillaume Sibertin-Blanc (2013, p. 102) lo que cuenta es "[...] la reciprocidad y no la oposición máquina de guerra/Estado, que está siempre determinada por un campo de coexistencia de todos los procesos maquínicos." 
Mi segunda hipótesis de trabajo es considerar la máquina de guerra como un aestheticscape, un paisaje estético, más que una acción de alisamiento de un régimen territorial. Me inspiro en el concepto de scapes de Arjun Apadurai (1990), dejados tras el rastro de una posmodernidad llena de interferencias por las intersecciones conflictivas entre flujos locales y globales, industrias culturales y cultura propia, etc. Guardo de este término esa vertiente de interconexión como configuradora de territorialidades (PERUGACHE, 2020), sin centro ni periferia, y cuya percepción del observador no depende de la posición del que mira. Un paisaje en el que las distancias no se divisan sin redistribuir, a cada instante, las regiones y las conexiones que agencian. Éstas se originan por contaminaciones cromáticas, intensidades, rugosidades, de modo que, a fuerza de ritmo, la topografía se frunce dejando pliegues, que afianzan nuevas distancias cada una de las cuales se modifican con el desplazamiento del observador.

A la luz de estas consideraciones, cuestiono: ¡cómo el coronavirus se delinea como paisaje estético? ¿Cómo surge? ¿Sobre qué tipo de territorio? ¿En qué medida funge como máquina de guerra? ¿Cómo se establece como herramienta de poder y de resistencia, al mismo tiempo?

\section{El Concepto de Máquina de guerra nómada de Deleuze y Guattari}

No me atrevo a ir tan lejos como Žižek (2020) en su afirmación de que el coronavirus asestó un golpe mortal al capitalismo. A estas alturas de la pandemia, no se avizora ese nuevo orden (TABORDA; RICCARDI, 2019). Con los planteamientos de los autores de referencia, sí, por el contrario, se puede trazar una genealogía que entrevera, como sarmientos, lo epidemiológico y el capitalismo. Las mil mesetas que escalan el esquizoanálisis de Deleuze y Guattari no nos lleva a un Estado permanente solidificado; consiste en la capacidad de generar "[...] nuevos conceptos que nos guíen en los diferentes tipos de agenciamientos y sus producciones" (AGOSTINHO, 2020, p. 125), cuyos tránsitos se dirimen en "[...] líneas, rizomas y máquinas abstractas." (GODANI, 2009, p. 172). Como afirma Francesco Lesce, nos encontramos ante una "imagen nómada del pensamiento" (LESCE, 2004, p. 79). Por eso, analiza el filósofo italiano, la máquina de guerra es una potencia del pensamiento "[...] irreductible al aparato del Estado, exterior a su soberanía y anterior a su derecho." (LESCE, 2004, p. 82). Muchos intérpretes de la obra de Deleuze y Guattari nos dan pistas sobre la relación entre máquina de guerra y Estado en el marco de su peculiar ontología, que podría caracterizarse 
como nómada (y de una forma nómada, pues hasta la nomadología está en continúa transmutación). Sibertin-Blanc pone el énfasis en una idea de Estado surgida en una zona de indeterminación en la que el aparato de poder se solapa con una transindividualización del deseo. Básicamente la forma estatal está envuelta en una fantasmagoría fabricada de los anhelos colectivos de una comunidad, que se encarna en un

Estado originario [...] operador de una toma del poder en las producciones transindividuales del inconsciente, que reorganiza los escenarios fantasmales en los cuales se regulan las identificaciones colectivas y los modos de subjetivación de los individuos sociales. (SIBERTIN-BLANC, 2013, p. 17).

Mollar es entender la ontología rizomática tanto del Estado como de la máquina de guerra si no queremos llegar al límite de que el propio aparato represivo estatal use un concepto tan revolucionario como la máquina de guerra para ejercer una violencia real, como puso en evidencia Christine Vollaire (2017), analizando las estrategias del ejército israelí con visos a intervenir bélicamente. Volviendo a Sibertin-Blanc, la nomadología es una herramienta que supera la dicotomía planteada. El problema, para el autor francés, radica en la asunción de una interioridad del Estado en sentido de su autopresuposición de la cual emergen unas coordenadas espacio-temporales, "[...] a saber: métodos de captura de la territorialidad en el seno de la cual el Estado aparece necesariamente como el único sujeto legítimo" (SIBERTIN-BLANC, 2013, p. 79). A estos métodos de organización, Deleuze y Guattari lo denominan técnica del estriaje del espacio, que hace del mismo una superficie homogénea, delimitada, organizada en segmentos identificables, controlable según puntos de referencia constantes que permiten apreciar, desde todas las posiciones, "[...] cualquier quiebre o variación de las cosas, hombres y signos." (DELEUZE; GUATTARI, 1980, p. 472). Es ahí que estos autores definen la máquina de guerra como una "forma pura de exterioridad" (SIBERTIN-BLANC, 2013, p. 79), que se plasma topológicamente en un alisamiento de los lugares:

Una de las tareas fundamentales del Estado es la de estriar el espacio sobre el que reina, o utilizar espacios lisos como un medio de comunicación al servicio de un espacio estirado. Para cualquier Estado no sólo es vital vencer al nomadismo, sino también controlar las migraciones y, más exactamente, reivindicar una zona de derechos sobre todo un "exterior", sobre el conjunto de flujos que atraviesan la ecúmene. (DELEUZE; GUATTARI, 1980, p. 479). 
Desde mi punto de vista, el concepto de máquina de guerra tiene que ver con una forma de proyectar geo-imaginarios, diferente a las jerarquías con las que las técnicas de estriaje organizan su cartografía. La máquina de guerra termina por asumir las variaciones y multiplicidades, lo que Deleuze y Guattari denominan "heccéités", que se dirimen en latitudes y longitudes, y en los que prevalecen las intensidades y las "singularidades virtuales" (DELEUZE; GUATTARI, 1980, p. 378). Como subraya Godani (2009, p. 167), “[...] antes que los rasgos intensivos y virtuales se organicen en sujetos y objetos, aquéllos no son más que dimensiones de una multiplicidad, es decir, una línea abstracta que identifica una hecceidad."

En la espacialidad lisa de la máquina de guerra, los elementos están concatenados y se relacionan por intensidades y variaciones. Por muy heterogéneos que sean, una tonalidad o una contaminación cromática permiten pasar de una fracción a otra sin perder la continuidad, "[...] son los gradientes los que marcan los devenires y los pasajes.” (DELEUZE; GUATTARI, 1972, p. 26). Y, sobre todo, sin que ningún elemento vea aminorada su potencia de agenciamiento, o lo que es lo mismo, su capacidad de propiciar el máximo número de conexiones, encuentros y desterritorializaciones. Como afirma Martin, se trata de pasar de "[...] una singularidad a otra sin volver al punto de salida, respiración de una corriente unívoca agitada de pliegues, desierto sedoso de olas ondulatorias cuyo mínimo cambio de velocidad desarrolla una nueva repartición de singularidades." (MARTIN, 1991, p. 60-61). De ahí mi afirmación de que la máquina de guerra delinee, como veremos en el capítulo que sigue, un aestheticscape, un paisaje estético. En consecuencia, la superficie es lisa no por la ausencia de elementos, sino por la agilidad de las conexiones facilitadas por las texturas y contaminaciones cromáticas.

El Estado estriado sería como un cuerpo al que se le quiere practicar una autopsia en una fría cama metálica de una morgue. El forense, antes de diseccionar, traza sobre la piel unas marcas discontinuas para guiar después al bisturí, que cartografía unos itinerarios en un mapa definitorio de funciones superpuesto a una corporalidad en rigor mortis. El Estado actúa sobre cadáveres exquisitos, lentamente, de ahí los trazos discontinuos. La anatomía (anatomé, $\alpha v \alpha \tau o \mu \eta)$ desterritorializada de la máquina de guerra no se deja enrigidecer, ni marcar con carboncillo, porque ya está plegada, declinada en infinitos "[...] polos, zonas, umbrales, gradientes.” (DELEUZE; GUATTARI, 1980, p. 164). Su alisamiento es consecuencia, paradójicamente, de una saturación de posibilidades infinitas de cortes (tomé, $\tau о \mu \eta$ ), orientados siempre hacia lo alto 
(anà, $\alpha v \alpha)$, "[...] que muestran la verticalidad de la experiencia y la tendencia de todo fenómeno a crecer por los inagotables vericuetos de la posibilidad." (ROMERO TENORIO, 2014, p. 191).

Una pregunta que surge es: ¿sobre qué territorio opera el Estado y la máquina de guerra? Godani afirma que la creatividad de la máquina de guerra "[...] consiste en la capacidad de generar espacios lisos o de alisar las estrías de un espacio organizado" (GODANI, 2009, p. 183), de manera que se libere las concatenaciones más dispares (BARTHOLD, 2018). Sin embargo, me inclino hacia la concepción de Sibertin-Blanc, para quien la exterioridad no es en el espacio (distancia geográfica), sino

[...] del espacio a sí mismo (ser "un afuera" no importa donde se esté), que impida su plena interiorización a la forma-Estado, en conformidad con la determinación del nomos nomádico: espacio liso que no puede ser tomado, sino solamente tenido, y que vuelven los correlatos territoriales (socio-económicos, institucionales, simbólicos) de un aparato de Estado activamente imposibles. (SIBERTIN-BLANC, 2013, p. 121).

Ni el Estado ni la máquina de guerra actuarían sobre un terreno liso a estriar, en el caso del primer actor, o uno estriado a alisar, en el del segundo. Es una cuestión de intensidades de elementos relacionales dispuestos en el mapa de forma concatenada, en el caso de la máquina de guerra, de tal manera que, si hay una relación entre ellos, se forja por variaciones tonales sobre una territorialidadterritorializante. Uso el participio presente porque esta geo-configuración está en una temporalidad topológica que la encadena a un presente que siempre está al límite de su acaecimiento (ROMERO, 2017). Lo latitudinal como atravesable y, al mismo tiempo, nunca atravesado; es el propio topos quien dirige la conformación espacial, creando zonas de iteración y de des-iteración. Desde una lógica cartográfica del Estado, el territorio es un libro con portada, lomo y páginas donde coletean miles de palabras como peces en las redes de un pescador. La máquina de guerra nómada opera sobre el libro no como topos, sino como horos, es decir, borde de su devenir evento. Comienzo a leer y las palabras escapan de las redes y navego de página en página sin encallar en sus arrecifes. Por ello, afirman Deleuze y Guattari (1980, p. 10):

No nos preguntaremos jamás qué quiere decir un libro, significado o significante, no buscaremos entender nada en un libro, nos preguntaremos con qué funciona, en conexión de qué hace pasar o no intensidades, en cuáles multiplicidades introduce y metamorfosea la suya [...] Un libro sólo existe por el afuera y afuera. 
Se puede concluir que la máquina de guerra es una praxis política más que un acto; un evento de territorialización antes que una forma de distribución de un territorio (LOZANO, 2018). De aquí se desprenden unos interrogantes: ¿la máquina de guerra puede ser un instrumento del Estado para ejercer su poder? Si es así, ¿de qué manera? ¿Puede facilitar el proceso de estriaje? ¿La guerra para la imposición de un status quo es el objetivo de esa máquina?

\section{Chaosmose del Covid-19 en cuanto máQuina de guerra nómada}

Sugerí en el capítulo anterior que lo que rodea y engulle a la máquina de guerra es un aestheticscape, en el que se evidencia antes que las jerarquías y las simetrías, las transiciones y las dislocaciones, entre - en nuestro caso los flujos políticos y estéticos (PORTER, 2009). Este paisaje está atravesado “[...] por ejes y umbrales, por latitudes, longitudes, geodésicos, por gradientes que marcan los devenires y los pasajes, los destinos de aquél que se desarrolla." (DELEUZE; GUATTARI, 1972, p. 26). A su "topología en tránsito" (ZDEBIK, 2019, p. 242) la ritman las rugosidades, tonalidades y contaminaciones cromáticas (y no las coordenadas fijas).

Ahora se trata de ubicar al covid-19 en ese paisaje donde la escala de tonalidades le confiere la potencialidad de ser un instrumento de estriaje y, al mismo tiempo, de alisamiento. Todo depende de las sucesivas osmosis por las diferencias de gradaciones de fluidos. En su último ensayo, Chaosmose (1992), Guattari nos abrió un complejo panorama donde las subjetividades políticas se configuran a medida que atraviesan las tres ecologías -sociales, mentales y ambientales-, generando universos simbólico-estéticos que enriquecen dichas subjetividades. Entiendo la estética como conexiones rizomáticas, que no necesitan de relaciones de oposición ni solapamientos. En una investigación sobre la resistencia de la comunidad indígena misak (Colombia) por medio del tejido, recogí testimonios que narraban las incursiones del paramilitarismo en el resguardo. Estos grupos criminales infringían terror con asesinatos; pero también minaban el biorritmo imponiendo toques de queda o dictando quién se relacionaba con quién (BUITRAGO, 2021). Y, sin embargo, los misak seguían tejiendo mientras recorrían su resguardo en silencio, embadurnándolo con su sentipensar. Por ello, la máquina de guerra nómada no es una oposición al estriaje del para-estado; su acción consiste en el enriquecimiento estético de "semiosferas" (LOTMAN, 1996) subjetivas. 
Los diversos grados de subjetivación van escamando el paisaje estético sin una organización topológica; más bien osmótica. Para comenzar, si el covid-19 emergió en este paisaje como técnica de estriaje o máquina de guerra, fue por caosmosis, en su sentido etimológico. Viene del griego $\omega \dot{\sigma} \mu o_{\varsigma}(\overline{\boldsymbol{o s s m o ́ s}})$, acción de empujar o impulso y el sufijo -sis, proceso. De esta manera el covid-19 va dejando rastros de subjetividades buceando por el paisaje estético; y si se dan coincidencias con un modo de organización de sometimiento o de insurgencia, es por el tránsito de fluidos por zonas de heterogéneas concentraciones, separadas por membranas porosas; el pasaje se produce por esa variedad de consistencias que empujan dichos fluidos, equilibrando sus grados de soluciones (más por gradaciones osmóticas que por la ontología de esos flujos). Por ello, la emergencia de la máquina de guerra no germina de la anarquía, del arké, desde un comienzo que arkêin (comanda) su desarrollo, sino desde un caos ( $\chi \alpha$ ós, khaos): espacialidad genealógica desordenada y que pertenece completamente a la praxis (los misak recorrían en silencio su resguardo dejando tras de sí, como huellas, territorios sentidos).

Cuando el baño químico remueve el papel de revelado de los paisajes estéticos, en esas reacciones de las sales de plata que ionizan los átomos en un barreño de plástico, se atisban las estructuras fantasmagóricas de las estrías con la que el pensamiento sedentario fija el territorio, además de desvelarnos “[...] el funcionamiento de la forma-estado que sobre-determina la sedentarización implícita de nuestras pragmáticas intelectuales." (SIBERTIN-BLANC, 2013, p. 78). No parece que ese virus que flota en un plasma que impregna la platina de un microscopio (figura 1, izquierda) sea tan mortífero:

Figura 1- Izquierda: Aestheticscape del covid-19, imagen de microscopio. Derecha: fotograma de Tiempos Modernos (1936) de Charles Chaplin.
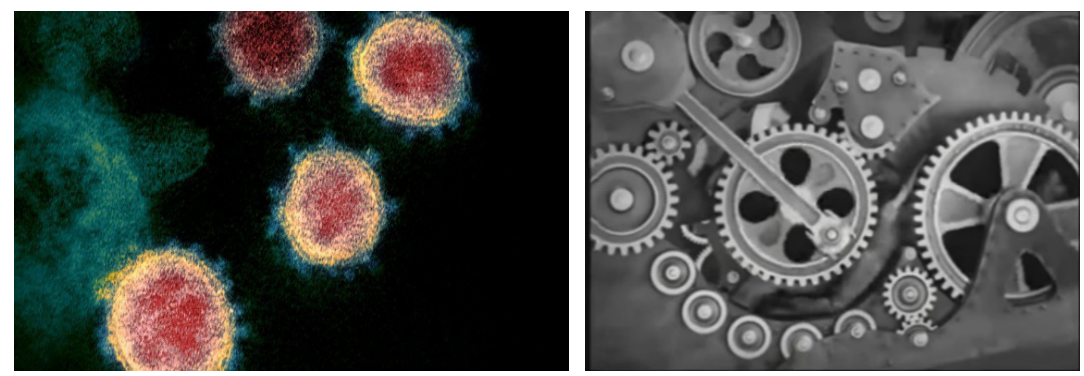

Fuente: Izquierda: Periódico electrónico BBC (https://www.bbc.com/ mundo/noticias-51510736). Derecha: captura de pantalla. 
En ese paisaje fantasmagórico, los engranajes del epidemiocapitalismo no necesitan fricciones para mover la maquinaria, como en la que se ve atrapada Charles Chaplin en Los Tiempos Modernos (figura 1, derecha). La mercancía del epidemiocapitalismo es gelatinosa, rueda en el vacío y su emplazamiento para ser expuesta ya no es el escaparate, como analizaba Walter Benjamin (2006), sino las frías pantallas de las tabletas o de los móviles. El flâneur divagaba por las galerías parisinas convirtiendo las mercancías en fantasmagorías, al no adquirirlas, y dichas vitrinas en altares de un capitalismo posaurático, por la relación de contemplación hacia el objeto. Si en las paredes de las iglesias se exhiben las doce estaciones del vía crucis, del escaparate desaparece todo resquicio de sacrificio que entrańa el proceso de producción fabril. En Instagram las mercancías no son para contemplarlas, sino para navegar en ellas en un proceso táctil. Como patas de ranas al saltar, los dedos las atrapan, agrandan, manipulan y, sin embargo, esta intensidad en el manejo nos termina devolviendo a la superficie; un simple deslizamiento lateral expulsa al producto y, en su puesto, otro (ROMERO; BUITRAGO; ECHEVERRY, 2017). La intensidad del deseo se reduce a la pulsión fría e inane del like que va al vertiginoso ritmo del tránsito de imágenes. Bajo cada producto hay una sala swinger, que un clic abre, habitada por cientos de personas abstraídas de cualquier coqueteo entre ellas. Una historia, una falda, una frase filosófica pueden congregar un sinnúmero de interacciones sin ninguna sinapsis entre ellas. Tal es así que el verdadero objeto de consumo ya no es la mercancía en sí, sino estas reacciones alienadas. El capitalismo se nutre de ese troquel, y el covid-19 que flota y divaga por el plasma es su paradigma. Por añadidura, las mercancías ya no tienen ciclo: ni el uso las desgasta ni la obsolescencia por el paso de moda. Ya pueda encantar o no, poco importa, siempre serán arrojadas al margen extradiegético de la interfaz táctil.

Cabe preguntarnos cómo ingresó la epidemia en el terreno social. Michel Foucault (1975) puso de relieve la organización de las poblaciones que sufrieron la peste en el s. XVII. Arrasaba como olas allá por dónde pasaba, estableciéndose una relación lineal entre la difusión del virus y la cartografía que pringaba. De ahí que se encerraran a los habitantes en sus casas y se entregasen las llaves a la policía, que pasaba lista, teniendo que responder cada uno con una aseveración sobre su estado de salud, asomándose por una pequeña ventanilla. Si la autoridad percibía que mentía, lo detenía. El SARS-CoV-2 inaugura un nuevo régimen de control basado en coordenadas móviles en la medida en que se sincronizan a los 
individuos con las trayectorias que delinea el covid-19 en su topografía. Antes que a un lugar físico, llegó a las redes sociales, diseminándose por medio de sus recursos: memes con grupos de amigos brindando con cerveza de marca Corona, plagados de hashtags graciosos o videos corriendo por Instagram en los que aparece gente gritando la denominación del virus como si de una arenga a un club de fútbol se tratara. En esta primera fase era un virus cool, y como tal, necesitaba visualizarse. Entonces pasó de la platina del microscopio a una representación simpática y colorida, cual es esa imagen que todos conocemos del covid-19:

Figura 2- Representación del SARS-CoV-2, causante del covid-19

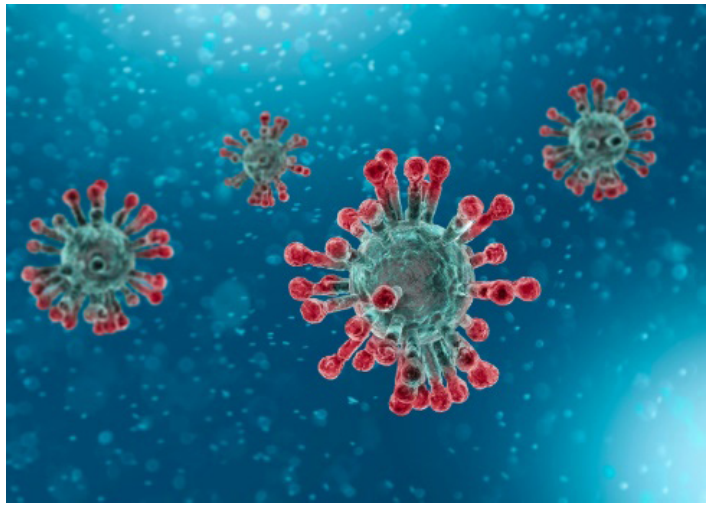

Fuente: Portal de El Médico Interactivo, (https://elmedicointeractivo.com/ el-periodo-de-incubacion-de-covid-19-se-situa-en-51-dias/).

Este paisaje estético estrió nuestro imaginario con una narrativa muy simple que hizo permanecer al virus en el plano de la vulnerabilidad: el jabón hacía que se desprendieran esas trompetas y se volvería inocuo en nuestras manos. Evitar la muerte es un acto simple, muy alejado de las grandes epopeyas, al igual que el deseo se limita a la vasectomía de una pulsión del dedo sobre un corazoncito.

\section{EPIDEMIOCAPITALISMO Y NET-(FL)ASC(IX)SMO}

La fantasmagoría del epidemiocapitalismo es la de la mercancía sin proceso: ni de producción ni de putrefacción, con el telón de fondo del ocio. En España, los medios de comunicación escenifican el heroísmo con que los 
ciudadanos están afrontando la pandemia: con ejercicio, aplaudiendo en los balcones, quedándose encerrados. Se censura toda referencia a la muerte, obviando imágenes de ataúdes. Jean Baudrillard (1976, p. 200) afirmaba, en este sentido, que "[...] desintrincar la vida de la muerte e imponer a la muerte y a los muertos la prohibición, éste es el primer punto de emergencia del control social. El poder sólo es posible si la muerte no es libre, si los muertos quedan bajo vigilancia."

El virus se convierte en un dispositivo de estriaje del campo social, en el que lo epidemiológico precede a la demografía. El pasaporte inmunológico con el que se quiere organizar a la población es el paradigma. Nos relata ByungChul Han que los países asiáticos, cuyos individuos son más disciplinados por una forma ancestral de colectivismo, aceptan de buen grado la "vigilancia digital" (HAN, 2020, p. 99) a la que están sometidos. Por el contrario, Europa, ante el pánico, cierra las fronteras a un enemigo exterior que, paradójicamente, son ellos mismos, ya que la pandemia afecta, sobre todo, en la primera ola, a los europeos del Mediterráneo. En Corea del Sur, las autoridades controlan los síntomas del coronavirus y vuelcan los datos en una aplicación que clasifica a los individuos como aptos o no para ir a trabajar o transitar por la calle. China sitúa cámaras con sensores térmicos en puntos estratégicos, como estaciones de tren; en el momento en que capten que una persona tenga fiebre, el sistema envía a las otras que compartieran lugares, como un vagón de tren, un mensaje por la aplicación. Ésta visualiza un mapa que muestra la posición de los posibles afectados.

No es nuevo que el big data organice nuestras decisiones individuales en el cerebro colectivo. Se ha llegado a un punto de sofisticación que ya no se amolda el producto al individuo; más bien, al contrario: el individuo al producto. Por ejemplo, en la campańa presidencial de 2016, el equipo de Donald Trump contrató a la empresa Cambridge Analytica (HEAWOOD, 2018). En los Estados clave donde unos pocos votos decantarían el color político, esta sociedad identificó, por medio del robo de datos de las redes sociales, a los indecisos, a quienes virilizaron con material (videos, infografías, fake news) en contra de Hillary Clinton. Adaptaron, por tanto, los individuos al producto electoral.

Otra forma de estriación del campo social es la implementación del ocio como estrategia de enfrentamiento al virus, identificando, en los recursos simbólicos y culturales de una clase media que se expresa en la virtualidad, un baluarte de resistencia. Como ya mencioné anteriormente, se presenta 
como acto heroico el hecho de quedarse en cómodas casas con todo tipo de entretenimiento. Básicamente nos movilizan, desmovilizándonos. Atiborrarse de contenidos de plataformas digitales como Netflix se eleva a acto de ciudadanía. Después, no hay que olvidar que estas ofertas de entretenimiento son instrumentos de clasificación de nuestros gustos (si hemos visto un tipo de película, nos recomendará, con porcentajes, una serie de contenidos, perfectamente jerarquizados). Los rankings cotidianos de los programas nos dan la medida del pathos de la sociedad.

El fascismo del ocio o net-(f)asc(ix)smo, a diferencia de los movimientos políticos incubados en el s. XIX y que eclosionaron en el XX, como el fascismo o el comunismo, es antiutópico. Ambos regímenes proyectaban al hombre nuevo, en el caso del marxismo, en el poscapitalismo, con un pensamiento universal y libre de todas las mitologías, que pudiera desarrollar su potencial humano con el conocimiento científico y desarrollar así sus inquietudes políticas, estéticas y morales. El ideal de hombre del fascismo se materializó en el futurismo italiano, cuyos artistas preconizaban la máquina como modelo de sociedad por su modernismo y sus rupturas con el pasado.

El net-(f)asc(ix)smo no tiene la utopía del hombre nuevo; amontona “seres superfluos" (ARENDT, 2004, p. 576) en habitáculos que acumulan likes, empobrecidos simbólicamente por el moldeamiento del individuo a la mercancía. Es el terror tras la inocuidad, seres abigarrados en campos de concentración abiertos. Lo quirúrgico de la máquina de guerra son sus incisiones en la temporalidad y no en el cuarteamiento de los espacios. De ahí la imposibilidad de imaginar a un hombre nuevo en el futuro, porque el régimen en el que vivimos se desarrolla en un eterno presente. Al final de cada año, un algoritmo de Facebook nos recuerda los grandes hits. Y asumimos que el sistema prediga nuestros gustos. El suicidio retransmitido en directo por Telegram u otras redes sociales es la aniquilación del tiempo de después en nombre de un renacimiento vírico de las cenizas de coltán. La esperanza es que se consuma la muerte como un producto de ocio, con sus subsecuentes reacciones.

\section{Conclusiones}

Tan seductor como ingenuo sería considerar que el poder haya estriado las zonas de incisión con un plan prediseñado; se encontró con un paisaje estético cuyas osmosis permitieron su fluir biopolítico. Los medios sociales 
fueron moldeando, con su capitalismo de likes, seres superfluos a los que no les molestaban ser vigilados; es más, les gusta, creando en torno a ello una economía del deseo sin eros ni tanatos. En este terreno abonado penetró la máquina de guerra nómada del coronavirus, y alisó una territorialidad ya vigilada, usando los artilugios del sistema: cámaras que midieran la temperatura de los individuos, que volcaran la información en una aplicación, que nos avisara de si alguien con síntomas se hallaba cerca de nosotros. Este régimen de vigilancia abierto estaba antes de que el sistema lo estriara. El verdadero golpe de estado de la máquina de guerra del coronavirus es el llamado a la lucha por medio de la desmovilización en un net-(fl)asc(ix)smo o totalitarismo del ocio: ¿Cómo será el próximo mayo 68? ¿Consistirá en ver series desde la casa?

El sistema operó asimismo a través de un alisamiento de las topografías temporales. Tanto la memoria como las expectativas están organizadas por el big data. La predicción no es del futuro, sino del presente; no aquél que imaginó Benjamin (1971) en sus tesis como el terreno en el que opera la historia con toda su potencia dialéctica; tan sólo donde se agolpan individuos superfluos que aman ser vigilados a la búsqueda de una fútil reacción. En este régimen los vanguardistas no son los artistas, sino los informáticos y los analistas de datos. La cultura no tiene respuesta ante ese bucle: ¿podríamos llamar arte a aquello que alimenta la dictadura del ocio?

En este paisaje estético se han fijado hasta tal punto las osmosis que es imposible el tránsito de flujos: el poder y los dominados coinciden como nunca en el deseo de vigilar y de ser vigilados; se moviliza a la población para la guerra, desmovilizándola tras la coartada de una dura resistencia surtida por la dictadura del ocio. La máquina de guerra nómada supone una perspectiva inédita en esta configuración del poder, desde la lógica de los cadáveres con los que la hegemonía riega sus territorializaciones (incluido el suyo propio). El excesivo estriaje de la anatomía social la ha estrangulado hasta que se ha tornado azulada, avizorándose las infinitas venas que muestran la vitalidad de un cuerpo convertido en autómata. A base de apretar la palometa, rosca tras rosca que pareciese imposible llegar a más, se acorcharon las terminaciones nerviosas. Paradójicamente, sólo nos podemos sentir libre en el hormigueo que aflora por el apretamiento de las correas. Como afirmaba Antonin Artaud (1979, p. 1069), "el cuerpo deja de ser penetrado en la propia penetración”.

Ese hormigueo se propaga como la máquina de guerra nómada en el paisaje estético. Resulta imposible discernir sus coordenadas, prolifera por un lado y otro, aletea acá y allá, se chocan y vuelven. Si el poder selecciona 
sus cadáveres y los avitualla para establecer sus funciones biológicas (legales, médicas, sexuales, reproductivas, etc.), la máquina de guerra nómada se los da ya fabricados. Unos cadáveres exquisitos que convulsionan y de cuya podredumbre se alimenta el sistema, al igual que a la utopía de un mundo nuevo de los jóvenes náufragos de El señor de las moscas la nutría la carne, en descomposición por gusanos, de la cabeza de jabalí clavada en una estaca, cual ídolo.

ROMERO TENORIO, J. M.; ANDRES ALVAREZ, W. Covid-19's nomadic war machine: Aestheticscapes of the epidemic-capitalism. Trans/form/ação, Marília, v. 44, n. 4, p. 267-284, Out./Dez., 2021.

\begin{abstract}
The coronavirus emerged in a space where both the power that opresses and the opressed coincide in the desire to watch and be watched, by the action of social networks, which generate superfluous beings that exchange their intimacy for a like. Hence, we come to a capitalism where epidemiology precedes demography (epidemic-capitalism): the population is organized according to the ultra-individual logic of pandemic control (immunological passports, monitoring of infections). With the concept of a nomadic war machine by Deleuze et Guattari, the covid-19 is analyzed as an aesthetic landscape in which the territorialities are defined from the edges that pollute and not from the coordinates that delimit them. Therefore, it is concluded that this perfect totalitarianism, which is called al que se denomina net-(fl)asc(ix)smo, can move towards forms of dissent.
\end{abstract}

Keywords: Deleuze. Guattari. Coronavirus. Nomadology. Net-(f)asc(ix)smo.

\title{
REFERENCIAS
}

AGOSTINHO, L. D. Guattari: máquinas e sujeitos políticos. Trans/form/ação, Brasil, v. 43, n.1, p. 103-126, 2020.

APADURAI, A. Disjuncture and Difference in the Global Cultural Economy. Theory, culture \& Society, UK, v.7, p. 295-310, 1990.

ARENDT, H. Los orígenes del totalitarismo. Madrid: Taurus, 2004.

ARTAUD, A. CEuvres Complètes, tome IX. Paris: Gallimard, 1979.

AYRES CAMURÇA, M. Um poder evangélico no estado brasileiro? Mobilização eleitoral, atuação parlamentar e presença no governo Bolsonaro. Nupem, Brasil, v. 12, n. 25 , p. 82-104, 2020. 
BARTHOLD, Ch. Resisting financialization with Deleuze and Guattari. New York: Routledge, 2018.

BAUDRILLARD, J. L'échange symbolique et la mort. Paris: Gallimard, 1976.

BENJAMIN, W. Thèses sur la philosophie de l'histoire. Paris: Denoël, 1971.

BENJAMIN, W. Paris. Capitale du XIXe siècle. Paris: Édition du Cerf, 2006.

BUITRAGO ECHEVERRY, C. Empoderamiento y resistencia de las mujeres desplazadas víctimas del conflicto armado colombiano del barrio Pinar del Río (Barranquilla).

Investigaciones Feministas, Madrid, v. 12, n. 1, p. 203-214, 2021.

DELEUZE, G. Différence et repétition. Paris: PUF, 1968.

DELEUZE, G; GUATTARI, F. L’Anti-CEdipe. Paris: Minuit, 1972.

DELEUZE, G; GUATTARI, F. Mille plateaux. Paris: Minuit, 1980.

DE JIMÉNEZ, A. ¡Despierta! Razones contra una vida en aislamiento. México: La Sombra de Prometeo, 2020.

FOUCAULT, M. Surveiller et Punir. Paris: Gallimard, 1975.

GODANI, P. Deleuze. Roma: Carocci, 2009.

GUATTARI, F. Chaosmose. Paris: Galilée, 1992.

HAN, B.-C. La emergencia viral y el mundo de mańana. In: AMADEO, P. (ed.). Sopa de Wuhan. Pensamiento contemporáneo en tiempos de pandemia. Buenos Aires: ASPO, 2020. p. $97-112$.

HEAWOOD, J. Pseudo-public political speech: Democratic implications of the Cambridge Analytica Scandal. Information Polity, USA, n. 23, p. 429-434, 2018.

LOTMAN, Y. La semiosfera. La semiótica de la cultura. Madrid: Cátedra, 1996.

LOZANO, E. Del concreto al film. Collectivus. Revista de Ciencias Sociales, Barranquilla, v. 5, n. 1, p. 16-39, 2018.

MAHEIRIE, K.; ARAGON, L. A.; BRUNIERE, M. F. A produção de uma máquina de guerra na criação estética do RAP. Quaderns de Psicologia, Brasil, v. 19, n. 1, p. 35-47, 2017.

MALDONADO, J.; PALENCIA, M.; SILVA, A. La máquina de guerra y el devenir del Estado: una lectura de Amalia de José Mármol desde la perspectiva filosófica de Deleuze y Guattari. Revista Temas, Bucaramanga, v. 3, n. 10, p. 11-27, 2016.

MARTIN, J-C. Variations. La philosophie de Gilles Deleuze. Paris: Payot, 1991.

PATTON, P. Plateau 12: 1227 AD: Treatise on Nomadology-The War Machine. In: SOMERS-HALL, H.; BELL, J.; WILLIAMS, J. (ed.). A Thousand Plateaus and Philosophy. Edinburgh: Edinburgh University Press, 2018. p. 206-222. 
PERUGACHE SALAS, J. A. Procesos de configuración territorial y conflitos por el agua en el municipio de Pasto, Colombia. Collectivus. Revista de Ciencias Sociales, Barranquilla, v. 7, n. 2, p. 73-90, 2020.

PORTER, R. Deleuze and Guattari. Aesthetics and Politics. Cardiff: University of Wales Press, 2009.

ROMERO TENORIO, J. Escritura de una aporía. Tránsitos y obstrucciones en los Grafos Existenciales de C. S. Peirce. Revista Pensamiento, Madrid, v. 70, n. 262, p. 177 $196,2014$.

ROMERO TENORIO, J. M. Instante y momento oportuno en los Grafos Existenciales de Chales S. Peirce. Por uma dimensión kairológica de la creatividad. Revista Pensamiento, Madrid, v. 73, n. 276, p. 301-318, 2017.

ROMERO TENORIO, J. M.; BUITRAGO ECHEVERRY, C.; ECHEVERRY BLANCO, M. R. ¿¿Deslizarse o sumergirse en la interfaz? El periodismo drone y la maquetación ergonómica del espacio. Estudios sobre el Mensaje Periodístico, Madrid, v. 23, n. 1, p. 257-272, 2017.

SIBERTIN-BLANC, G. Politique et État chez Deleuze et Guattari. Essai sur le matérialisme historique-machinique. Paris: Presses Universitaires de France, 2013.

TABORDA, J. A.; RICCARDI, D. La cooperación internacional para la paz en Colombia: los casos de Estados Unidos y de la Unión Europea (1998-2016).

Geopolítica(s), Madrid, v. 10, n. 1, p. 107-134, 2019.

VOLLAIRE, C. L'usage des concepts. L'enrôlement des « machines de guerre " dans la guerre réelle. In: JEDRZEJEWSKI, F.; MARTIN, J.-C. (ed.), Deleuze, philosophe des multiplicités. Paris: L'Harmattan, 2017. p. 191-199.

WIDDER, N. Deleuze and Guattari's "War Machine" as a Critique of Hegel's Political Philosophy. Hegel Bulletin, UK., v. 39, n. 2, p. 304-325, 2018.

ZDEBIK, J. Deleuze and the map-image. Aesthetics, Information, Code, and Digital Art. New York: Bloomsbury Visual Arts, 2019.

ŽIŽEK, S. El coronavirus es un golpe al capitalismo a lo Kill Bill. In: AMADEO, P. (ed.). Sopa de Wuhan. Pensamiento contemporáneo en tiempos de pandemia. Buenos Aires: ASPO, 2020. p. 21-38.

Recebido: 23/4/2020

Aceito: 06/5/2021 
ROMERO TENORIO, J. M.; ANDRES ALVAREZ, W. 